Suning: Identifikasi Sektor Ekonomi Basis (Unggulan) dan Hierarki Pusat Pelayanan Berdasarkan Tingkat Kemampuan Fasilitas Dalam Rangka Pengembangan Wilayah (Studi Kecamatan Kasiman dan Kecmatan Padangan Kabupaten Bojonegoro.

\title{
Identifikasi Sektor Ekonomi Basis (Unggulan) dan Hierarki Pusat Pelayanan Berdasarkan Tingkat Kemampuan Fasilitas Dalam Rangka Pengembangan Wilayah (Studi Kecamatan Kasiman dan Kecamatan Padangan Kabupaten Bojonegoro)
}

\author{
Oleh : Suning
}

\begin{abstract}
Abstrak
Sesuai dengan kebijaksanaan pembangunan tingkat nasional dalam UU No. 24 tahun 1992 tentang Penataan Ruang bahwa kawasan perbatasan merupakan kawasan strategis dan diprioritaskan pembangunannya secara nasional. Kebijaksanaan pembangunan daerah Kabupaten Bojonegoro ditetapkan untuk mengarahkan pembangunan daerah untuk tercapainya keseimbangan dalam hal tingkat kemakmuran antar SWP. Dalam rangka mencapai keseimbangan pembangunan tersebut, maka penelitian ini bertujuan untuk mengidentifikasi sektor ekonomi basis (unggulan) dan hierarki pusat pelayanan berdasarkan tingkat kemampuan fasilitas kecamatan.

Penelitian ini dilakukan dengan menggunakan alat analisis (LQ) Location Quotient, (SSPS) Shift-Share Proportionality Shift, kombinasi LQ dengan SSPS. Kedua alat analisis ini diperoleh gambaran komoditi unggulan dengan klasifikasi tipe 1, 2, 3, dan 4 di masing-masing kecamatan pada wilayah studi. Sedangkan untuk mengetahui kemampuan kecamatan dalam memberikan pelayanan terhadap masyarakat digunakan alat analisis Scalogram. Hasil penelitian diperoleh gambaran bahwa Kecamatan yang memiliki klasifikasi tipe 1 adalah Kecamatan Padangan, artinya bahwa Kecamatan ini memiliki komoditi unggulan yang mampu memenuhi kebutuhan daerahnya dan daerah lain, karena komoditi ini memiliki pertumbuhan yang cepat di tingkat kecamatan. Sedangkan klasifikasi tipe 2 adalah Kecamatan Kasiman, artinya bahwa Kecamatan ini memiliki komoditi unggulan yang mampu memenuhi kebutuhan daerahnya dan daerah lain, tetapi komoditi ini memiliki pertumbuhan yang relatif lambat di tingkat kecamatan. Sedangkan berdasarkan hasil perhitungan analisis scalogram dapat diketahui bahwa kecamatan yang mempunyai fasilitas terlengkap adalah kecamatan yang memiliki peringkat 1 dari keseluruhan fasilitas kecamatan adalah Kecamatan Kasiman, yang mana kecamatan ini memiliki fasilitas kesehatan dan fasilitas ekonomi terlengkap dibanding dengan kecamatan lain. Kemudian Kecamatan Padangan memiliki peringkat 2 dari keseluruhan unit fasilitas kecamatan yaitu fasilitas kesehatan dan fasilitas pendidikan paling lengkap dibanding dengan kecamatan lainnya.
\end{abstract}

Kata Kunci : Hierarki pelayanan, Scalogram, Sektor basis

\section{PENDAHULUAN}

Kabupaten Bojonegoro memiliki luas sejumlah $230.706 \mathrm{Ha}$, dengan jumlah penduduk sebesar 1.176.386 jiwa yang merupakan bagian dari wilayah propinsi Jawa Timur dengan jarak $\pm 110 \mathrm{Km}$ dari ibukota Propinsi Jawa Timur dan terletak pada posisi $6^{\circ} 59^{\prime}$ sampai dengan $7^{\circ} 37^{\prime}$ Lintang Selatan dan $111^{\circ} 25^{\prime}$ sampai dengan $112^{\circ} 09^{\prime}$ Bujur Timur. Kabupaten Bojonegoro memiliki batas wilayah bagian Utara berbatasan dengan Kabupaten Tuban, bagian Timur berbatasan dengan Kabupaten Lamongan, bagian Selatan berbatasan dengan Kabupaten Madiun, Nganjuk dan Jombang. Sedangkan bagian Barat berbatasan dengan Kabupaten Ngawi dan Blora (Jawa Tengah). Wilayah studi yang dilakukan dalam penelitian ini adalah Perbatasan Kabupaten Bojonegoro bagian Barat yang terdiri dari dua Kecamatan yaitu Kecamatan Padangan dan Kecamatan Kasiman. Kecamatan ini harus mendapatkan perhatian lebih dari Kabupaten Bojonegoro terutama dalam perkembangan ekonominya.

*) Dosen Perencanaan Wilayah dan Kota (PWK) Universitas PGRI Adi Buana Surabaya 
Suning: Identifikasi Sektor Ekonomi Basis (Unggulan) dan Hierarki Pusat Pelayanan Berdasarkan Tingkat Kemampuan Fasilitas Dalam Rangka Pengembangan Wilayah (Studi Kecamatan Kasiman dan Kecmatan Padangan Kabupaten Bojonegoro.

Misalnya; Kecamatan Padangan memiliki potensi peternakan dan industri rumah tangga; Kecamatan Kasiman memiliki potensi perikanan, dan kerajinan kayu. Terkait dengan kawasan perbatasan, kebijaksanaan pembangunan tingkat nasional telah menetapkan dalam UU No. 24 tahun 1992 tentang Penataan Ruang dikatakan bahwa kawasan perbatasan merupakan kawasan strategis dan diprioritaskan pembangunannya secara nasional. Kemudian sebagai tindak lanjut dari UU tersebut diterbitkan Keppres No. 44 tentang Badan Pengendali Pembangunan Kawasan Perbatasan.

Penataan Ruang merupakan suatu proses perencanaan tata ruang, pemanfaatan ruang dan pengendalian pemanfaatan ruang. Kawasan perbatasan Kabupaten Bojonegoro merupakan salah satu kawasan perbatasan yang direncanakan pengembangannya dalam rangka meningkatkan pertumbuhan ekonomi dengan mengembangkan potensi ekonomi di masing-masing kecamatan. Dengan menggunakan asas kesesuaian penataan ruang diharapkan pengembangan potensi wilayah mampu bersaing di pasar global dengan produk daya saing yang dimiliki.

Kecamatan yang diprioritaskan pengembangannya adalah kecamatan yang diperkirakan akan cepat berkembang di masa yang akan datang, baik karena kekuatan internal yang terdapat di kecamatam tersebut maupun karena adanya investor baru yang akan masuk ke wilayah tersebut. Kecamatan yang berkembang akan mendorong kecamatan yang berdekatan untuk turut berkembang. Kecamatan yang berkembang perlu ditindaklanjuti dengan pengembangan sektor lain yang bersinergi dan perencanaan penyediaan fasilitas kepentingan umum. Kawasan perbatasan Kabupaten Bojonegoro dengan berbagai potensinya diharapkan dapat menjadi kabupaten yang generatif bagi daerah sekitarnya dalam pengembangan segala aktivitas khususnya aktivitas ekonomi.

Melihat tingkat strategisnya kawasan perbatasan di Kabupaten Bojonegoro, maka perlu ada kebijakan dalam penataan ruang yang ditentukan dengan tujuan untuk menganalisis dan mengetahui sektor basis (unggulan) ekonomi kecamatan, serta untuk mengetahui hierarki pusat Pelayanan berdasarkan Tingkat Kemampuan Fasilitas di Kecamatan Kasiman dan Kecamatan Padangan.

\section{METODE PENELITIAN}

Variabel yang digunakan dalam penelitian ini adalah variabel ekonomi yang terdiri dari indikator produksi komoditi dan PDRB. Sedangkan untuk mengukur hierarki pelayanan berdasarkan tingkat kemampuan fasilitas di Kecamatan Kasiman dan Kecamatan Padangan adalah; pertama, fasilitas yang berkaitan dengan aktivitas ekonomi, fasilitas ini menunjukkan bahwa adanya struktur kegiatan ekonomi lingkungan yang komplek, jumlah dan tipe fasilitas komersial akan menunjukkan derajat ekonomi kawasan/kota dan kemungkinan akan menarik sebagai tempat tinggal. Fasilitas yang berkaitan dengan aktifitas ekonomi yang dimaksud diantaranya seperti fasilitas: Luas lahan pertanian pangan, Luas lahan pertanian polowijo, Koperasi, Induatri dan Warung/pertokoan. Kedua, fasiltas yang berkaitan dengan aktivitas sosial, Fasilitas ini menunjukkan tingkat kegiatan sosial dari kawasan / kota. Fasilitas tersebut dimungkinkan tidak seratus persen merupakan kegiatan sosial, namun pengelompokkan tersebut masih dimungkinkan jika fungsi sosialnya relatif lebih besar dibandingkan sebagai usaha yang berorientasi pada keuntungan. Fasilitas yang berkaitan dengan aktifitas sosial yang dimaksud diantaranya seperti fasilitas: Kesehatan, tenaga medis, lembaga pendidikan, dan rumah sakit.

Adapun metode analisis yang digunakan, antara lain :

1. Analisis Location Quotient (LQ) dengan keunggulan dapat menunjukkan spesialisasi relatif (kemampuan) wilayah/kecamatan dalam suatu kegiatan ekonomi, tetapi tidak dapat menjelaskan faktor penyebab terjadinya perubahan dari suatu kegiatan.

2. Analisis Shift-Share Proportionality Shift (SSPS) memiliki keunggulan dapat melihat pertumbuhan dari suatu kegiatan terutama melihat perbedaan pertumbuhan baik skala yang lebih luas maupun dalam skala yang lebih kecil dengan mengetahui faktor penyebab terjadinya perubahan suatu kegiatan.

3. Kombinasi LQ dengan SSPS, keunggulannya adalah dapat diketahuinya sumber potensi wilayah/kecamatan dengan kategori tingkat pertumbuhan kecamatan yang cepat tumbuh maupun lambat tumbuh. 
Suning: Identifikasi Sektor Ekonomi Basis (Unggulan) dan Hierarki Pusat Pelayanan Berdasarkan Tingkat Kemampuan Fasilitas Dalam Rangka Pengembangan Wilayah (Studi Kecamatan Kasiman dan Kecmatan Padangan Kabupaten Bojonegoro.

4. Analisis Scalogram keunggulan analisis ini adalah dapat memberikan skor pada fasilitas yang dimiliki oleh masingmasing wilayah/kecamatan, namun tidak ada ukuran standart dalam pemberian nilai sehingga hanya berdasarkan pada kebutuhan prioritas saja.

\section{HASIL DAN PEMBAHASAN Lokasi}

Ruang lingkup wilayah studi adalah Kecamatan Kasiman dan Kecamatan Padangan dengan aktifitas mengidentifikasi sektor ekonomi basis atau unggulan dan mengidentifikasi hierarki pelayanan kecamatan berdasarkan tingkat kemampuan kecamatan.

\section{Kondisi Eksisting}

Kecamatan Padangan terletak \pm 33

$\mathrm{km}$ arah Barat dari pusat Kota Bojonegoro dengan luas $\pm 4.200 \mathrm{Ha}$ dengan batas geografis:

1. Sebelah Utara : Batas Administrasi Kecamatan Kasiman

2. Sebelah Timur : Batas Administrasi Kecamatan Purwosari

3. Sebelah Selatan : Batas Administrasi Kecamatan Ngraho dan Kecamatan Tambakrejo

4. Sebelah Barat : Batas Administrasi Kecamatan Dander

Kecamatan Padangan terbagi atas 16 desa dengan kepadatan rata-rata 13 jiwa/Ha. Mata pencaharian penduduk di kecamatan Padangan mayoritas petani dan buruh tani hal ini mencerminkan karakteristik Kecamatan Padangan merupakan kawasan pertanian, sebagaimana yang ditetapkan dalam SWP IV dengan arah pengembangan pertaninan, peternakan dan industri, dengan potensi komoditi padi, ubi kayu, kacang tanah, kedelai, kacang hijau, kelapa, sapi, pasir, tahu dan industri ledre.

Kecamatan Padangan memiliki jalan kolektor primer yang menghubungkan Kota Cepu dengan Kota Bojonegoro, Kota Cepu dengan Kota Ngawi, Kota Bojonegoro dengan Kota Ngawi serta memiliki jalan lokal primer yang menghubungkan Kecamatan Padangan dengan Kecamatan atau desa disekitarnya sehingga mudah dijangkau oleh penduduk. dibagian $\begin{gathered}\text { Kecamatan } \\ \text { utara }\end{gathered} \begin{gathered}\text { Kasiman terletak } \\ \text { wilayah }\end{gathered}$ Bojonegoro. Dengan batas geografis:

1. Sebelah Utara :Batas Administrasi Kecamatan

Kedewan

2. Sebelah Selatan : Batas Administrasi Kecamatan Padangan

3. Sebelah Timur : Batas Administrasi Kecamatan Kalitidu

4. Sebelah Barat : Batas Administrasi Propinsi Jawa Tengah

Kecamatan Kasiman merupakan wilayah Kabupaten Bojonegoro yang memiliki luas wilayah $4200 \mathrm{Ha}$ dengan jumlah penduduk 51.517 jiwa dan terdiri dari 7.138 KK. Secara administrasi Kecamatan Kasiman terdiri dari 10 desa dengan mayoritas penduduknya bermata pencaharian sebagai petani. Kecamatan Kasiman ditetapkan dalam SWP IV dengan arah pengembangan perikanan, perkebunan dan pertanian. Kecamatan ini memiliki potensi komoditi padi, kacang tanah, kacang hijau, tebu, kelapa, sapi, bubut kayu, genteng dan hasil perikanan dari kolam. Dari potensi ini diharapkan Kecamatan Kasiman mampu berkembang sebagaimana yang ditetapkan dalam SWP.

Adapun sistem transportasi yang terdapat di Kecamatan Kasiman sebagai berikut :

1. Sistem Jaringan Jalan Primer, yaitu Jalan Lokal Primer yang menghubungkan antara kecamatan Kasiman dengan kecamatan Kedewan, Kecamatan Padangan, dan Kecamatan Kalitidu serta desa disekitarnya

2. Sistem Jaringan Jalan Sekunder, yaitu jalan pelayanan kota yang terdiri dari :

a. Jalan Arteri Sekunder, yaitu jalan utama kota kecamatan yang menghubungkan antara kegiatan pelayanan kecamatan Kasiman dengan wilayah kecamatan lain (jalan urat nadi)

b. Jalan Kolektor Sekunder, yaitu jalan pengumpul atau jalan penghubung antara jalan lokal dengan jalan arteri sekunder

c. Jalan Lokal Sekunder, yaitu jalan dalam kota yang berasal dari pemukiman atau menghubungkan antara pusat lingkungan terkecil.

Analisis Location Quotient 
Suning : Identifikasi Sektor Ekonomi Basis (Unggulan) dan Hierarki Pusat Pelayanan Berdasarkan Tingkat Kemampuan Fasilitas Dalam Rangka Pengembangan Wilayah (Studi Kecamatan Kasiman dan Kecmatan Padangan Kabupaten Bojonegoro.

Analisis LQ digunakan untuk menentukan kategori suatu komoditi termasuk dalam komoditi basis atau bukan basis. Komoditi basis merupakan komoditikomoditi yang mempunyai peranan kuat di suatu daerah bila dibandingkan dengan peranan komoditi yang sama di daerah lain. Komoditi ekonomi dikatakan kuat apabila komoditi tersebut tidak hanya melayani pasar di daerahnya sendiri, tetapi juga mampu melayani pasar di daerah lain. Dari hasil perhitungan yang diperoleh, dapat diartikan dalam dua kategori, yaitu:

1. Bila nilai $L Q$ lebih kecil atau sama dengan 1 , menunjukkan bahwa komoditi tersebut bukan komoditi basis atau non unggulan..

2. Bila nilai $L Q$ lebih besar dari 1, menunjukkan bahwa komoditi tersebut adalah komoditi basis atau unggulan.

Berdasarkan hasil analisis LQ dapat diketahui komoditi-komoditi basis maupun non basis di masing-masing kecamatan. Seperti pada tabel 1 .

Tabel 1.

Location Quotient (LQ) Komoditi Unggulan Kecamatan Padangan dan Kecamatan Kasiman Tahun 2004

\begin{tabular}{llll}
\hline \multirow{2}{*}{ No } & \multirow{2}{*}{ Jenis Komoditi } & \multicolumn{2}{c}{ Kecamatan } \\
& & Padangan & Kasiman \\
\hline I & Tanaman Pangan & & \\
1.1 & Padi & SB & SB \\
1.2 & Jagung & BSB & BSB \\
1.3 & Ubi Kayu & SB & BSB \\
1.4 & Ubi Jalar & BSB & BSB \\
1.5 & Kacang Tanah & SB & SB \\
1.6 & Kedelai & SB & BSB \\
1.7 & Kacang Hijau & SB & SB \\
II & Tanaman & & \\
2.1 & Kerkebunan & & \\
2.2 & Kapuk Randu & BSB & BSB \\
2.3 & Jambu Mete & BSB & BSB \\
2.4 & Tembakau ( Virginia) & BSB & BSB \\
2.5 & Tembakau (Jawa) & BSB & BSB \\
2.6 & Tebu & SB & SB \\
2.7 & Kunyit & BSB & BSB \\
2.8 & Kencur & BSB & BSB \\
2.9 & Lengkuas & BSB & BSB \\
III & Populasi Ternak & & \\
3.1 & Sapi & BSB & SB \\
3.2 & Kerbau & BSB & BSB \\
& & &
\end{tabular}

\begin{tabular}{|c|c|c|c|}
\hline \multirow{2}{*}{ No } & \multirow{2}{*}{ Jenis Komoditi } & \multicolumn{2}{|c|}{ Kecamatan } \\
\hline & & Padangan & Kasiman \\
\hline 3.3 & Kuda & BSB & BSB \\
\hline 3.4 & Kambing & BSB & BSB \\
\hline $\begin{array}{l}3.5 \\
\text { IV }\end{array}$ & $\begin{array}{l}\text { Domba } \\
\text { Produksi } \\
\text { Penggalian }\end{array}$ & SB & BSB \\
\hline 4.1 & Batu Kapur & BSB & BSB \\
\hline 4.2 & Pasir & SB & SB \\
\hline 4.3 & Lainnya & SB & BSB \\
\hline v & \multicolumn{3}{|l|}{ Produksi Perikanan } \\
\hline 5.1 & Keramba & BSB & BSB \\
\hline 5.2 & Kolam & BSB & BSB \\
\hline 5.3 & Tambak & BSB & BSB \\
\hline v & \multicolumn{3}{|l|}{ Produksi Perikanan } \\
\hline 5.1 & Keramba & BSB & BSB \\
\hline 5.2 & Kolam & BSB & BSB \\
\hline 5.3 & Tambak & BSB & BSB \\
\hline 6.4 & Anyaman Bambu & BSB & BSB \\
\hline 6.5 & Anyaman Pandan & BSB & BSB \\
\hline 6.6 & Gerabah & BSB & BSB \\
\hline 6.7 & Bubut Kayu & BSB & SB \\
\hline 6.8 & Genteng & BSB & SB \\
\hline \multirow{2}{*}{\multicolumn{2}{|c|}{$\begin{array}{l}6.9 \text { mebel } \\
\text { Jumlah Komoditi } \\
\text { Unggulan }\end{array}$}} & BSB & BSB \\
\hline & & 11 & 9 \\
\hline
\end{tabular}

Sumber: Kecamatan dalam angka

Kabupaten Bojonegoro 2004 diolah

Keterangan :

1. $\mathrm{SB}=$ Sektor Basis

2. $\mathrm{BSB}=$ Bukan sektor basis

Berdasarkan LQ pada tabel 1di atas dapat diketahui bahwa:

Kecamatan Padangan memiliki komoditi unggulan sebanyak 11 komoditi terdiri dari : Padi, ubi kayu, kacang tanah, kedelai, kacang hijau, kelapa, sapi, pasir, penggalian lainnya, tahu dan ledre. Kecamatan Purwosari memiliki komoditi unggulan sebanyak 9 antara lain; Padi, kacang tanah, kacang hijau, tebu, kelapa, sapi, bubut kayu, genteng, dan kolam.

\section{Analisis Shift-Share}

Analisis Shift-Share yang digunakan dalam penelitian ini adalah Shift-Share Proportional Shift. Keunggulan dari analisis ini adalah dapat mengetahui komoditi apa saja yang memiliki pertumbuhan relatif cepat pada masing-masing Kecamatan, artinya jika nilai Proportionality Shift adalah positif, maka komoditi tersebut mempunyai pertumbuhan yang relatif cepat di tingkat Kecamatan. Sebaliknya jika nilai 
Suning : Identifikasi Sektor Ekonomi Basis (Unggulan) dan Hierarki Pusat Pelayanan Berdasarkan Tingkat Kemampuan Fasilitas Dalam Rangka Pengembangan Wilayah (Studi Kecamatan Kasiman dan Kecmatan Padangan Kabupaten Bojonegoro.

Proportionality Shift adalah negatif, maka komoditi tersebut memiliki pertumbuhan yang relatif lambat di tingkat Kecamatan. Kemudian untuk mendapatkan hasil yang lebih akurat, maka dari perhitungan ShiftShare Proportionality Shift tersebut dikombinasikan dengan hasil perhitungan Location Quotient.

$$
\text { Hasil perhitungan Shift-Share }
$$

Proportionality Shift dijelaskan bahwa :

\section{a. Kecamatan Padangan}

Kecamatan Padangan memiliki komoditi dengan pertumbuhan yang relatif cepat maupun komoditi dengan pertumbuhan yang relatif lambat. Komoditi dengan pertumbuhan yang relatif cepat antara lain; kacang tanah, tebu, kerbau, domba, pasir, tahu, ledre. Sedangkan komoditi dengan pertumbuhan yang relatif lambat adalah; padi, jagung, ubi kayu, kedelai, kacang hijau, kelapa, sapi dan kuda.

\section{b. Kecamatan Kasiman}

Kecamatan Kasiman memiliki komoditi dengan pertumbuhan yang relatif cepat antara lain; padi, kacang tanah, bubut kayu, genteng, tebu, kunyit, dan domba. Sedangkan komoditi dengan pertumbuhan yang relatif lambat adalah jagung, kacang hijau, kelapa, tembakau virginia, tembakau jawa, sapi, kerbau, kambing, dan pasir.

Perhitungan Shift - Share

Proportionality Shift sebagaimana pada tabel 2.

Tabel 2.

Nilai Shift - Share Proportionality Shift (SSPS) Komoditi Unggulan

Kecamatan Padangan dan Kecamatan Kasiman

\begin{tabular}{|c|c|c|c|}
\hline \multirow{2}{*}{ No } & \multirow{2}{*}{ Jenis Komoditi } & \multicolumn{2}{|c|}{ Kecamatan } \\
\hline & & Padangan & Kasiman \\
\hline I & Tanaman Pangan & & \\
\hline 1.1 & Padi & - & + \\
\hline 1.2 & Jagung & - & - \\
\hline 1.3 & Ubi Kayu & - & 0 \\
\hline 1.4 & Ubi Jalar & 0 & 0 \\
\hline 1.5 & Kacang Tanah & + & + \\
\hline 1.6 & Kedelai & - & 0 \\
\hline 1.7 & $\begin{array}{l}\text { Kacang Hijau } \\
\text { Tanaman }\end{array}$ & - & - \\
\hline II & Perkebunan & & \\
\hline 2.1 & Kelapa & - & - \\
\hline
\end{tabular}

\begin{tabular}{|c|c|c|c|}
\hline \multirow{2}{*}{ No } & \multirow{2}{*}{ Jenis Komoditi } & \multicolumn{2}{|c|}{ Kecamatan } \\
\hline & & Padangan & Kasiman \\
\hline 2.2 & Kapuk Randu & 0 & 0 \\
\hline 2.3 & Jambu Mete & 0 & 0 \\
\hline 2.4 & Tembakau ( Virginia) & 0 & - \\
\hline 2.5 & Tembakau (Jawa) & 0 & - \\
\hline 2.6 & Tebu & + & + \\
\hline 2.7 & Kunyit & 0 & + \\
\hline 2.8 & Kencur & 0 & 0 \\
\hline 2.9 & Lengkuas & 0 & 0 \\
\hline III & Populasi Ternak & & \\
\hline 3.1 & Sapi & - & - \\
\hline 3.2 & Kerbau & + & - \\
\hline 3.3 & Kuda & - & 0 \\
\hline 3.4 & Kambing & - & - \\
\hline 3.5 & Domba & + & + \\
\hline IV & Produksi Penggalian & & \\
\hline 4.1 & Batu Kapur & + & 0 \\
\hline 4.2 & Pasir & + & - \\
\hline 4.3 & Lainnya & - & + \\
\hline V & Produksi Perikanan & & \\
\hline 5.1 & Keramba & 0 & + \\
\hline 5.2 & Kolam & + & + \\
\hline 5.3 & Tambak & + & + \\
\hline V & Produksi Perikanan & & \\
\hline 5.1 & Keramba & 0 & 0 \\
\hline 5.2 & Kolam & 0 & 0 \\
\hline 5.3 & Tambak & 0 & 0 \\
\hline 6.4 & Anyaman Bambu & 0 & 0 \\
\hline 6.5 & Anyaman Pandan & 0 & 0 \\
\hline 6.6 & Gerabah & 0 & 0 \\
\hline 6.7 & Bubut Kayu & 0 & 0 \\
\hline 6.8 & Genteng & 0 & 0 \\
\hline 6.9 & mebel & 0 & 0 \\
\hline Sun & Kecamatan & dalam & angka \\
\hline $\begin{array}{l}\text { Kab } \\
\text { diol }\end{array}$ & paten Bojonegoro & $2003 c$ & an 2004 \\
\hline
\end{tabular}

\section{Penentuan Klasifikasi Tipe Komoditi Unggulan Kecamatan}

Untuk memperoleh hasil yang akurat dalam menentukan klasifikasi komoditi unggulan masing-masing kecamatan yang memiliki pertumbuhan relatif cepat maupun memiliki pertumbuhan relatif lambat adalah dengan menggunakan kombinasi Location Qoutient dengan Shift-Share Proportionality Shift yang terdiri dari empat tipe yaitu: 
Suning : Identifikasi Sektor Ekonomi Basis (Unggulan) dan Hierarki Pusat Pelayanan Berdasarkan Tingkat Kemampuan Fasilitas Dalam Rangka Pengembangan Wilayah (Studi Kecamatan Kasiman dan Kecmatan Padangan Kabupaten Bojonegoro.

\begin{tabular}{ccl}
\hline Tipe & Nilai & \multicolumn{1}{c}{ Kriteria } \\
\hline 1 & $\mathrm{LQ}>1$ dan $\mathrm{PS}>0$ & Sektor basis yang pertumbuhannya cepat \\
2 & $\mathrm{LQ}>1$ dan $\mathrm{PS}<0$ & Sektor basis yang pertumbuhannya lambat \\
3 & $\mathrm{LQ}<1$ dan $\mathrm{PS}>0$ & Sektor bukan basis yang pertumbuhannya cepat \\
4 & $\mathrm{LQ}<1$ dan $\mathrm{PS}<0$ & Sektor bukan basis yang pertumbuhannya lambat \\
\hline \multicolumn{2}{l}{ Hasil perhitungan kombinasi Location Quotient dengan Shift-Share Proportionality Shift }
\end{tabular}
komoditi ekonomi di masing-masing kecamatan secara lengkap dapat di lihat pada tabel 3.

Tabel 3.

Klasifikasi Komoditi Ekonomi Terpilih Masing-Masing Kecamatan

Berdasarkan Location Quotient dan Proporsional Shift

\begin{tabular}{|c|c|c|c|}
\hline \multirow{2}{*}{ No } & \multirow{2}{*}{ Jenis Komoditi } & \multicolumn{2}{|c|}{ Kecamatan } \\
\hline & & Padangan & Kasiman \\
\hline I & Tanaman Pangan & & \\
\hline 1.1 & Padi & Tipe 2 & Tipe 1 \\
\hline 1.2 & Ubi Kayu & Tipe 2 & - \\
\hline 1.3 & Ubi Jalar & - & - \\
\hline 1.4 & Kacang Tanah & Tipe 1 & Tipe 1 \\
\hline 1.5 & Kedelai & Tipe 2 & - \\
\hline 1.6 & Kacang Hijau & Tipe 2 & Tipe 2 \\
\hline II & Tanaman Perkebunan & & \\
\hline 2.1 & Kelapa & - & Tipe 2 \\
\hline 2.2 & Tebu & Tipe 1 & Tipe 1 \\
\hline III & Populasi Ternak & & \\
\hline 3.1 & Sapi & - & Tipe 2 \\
\hline 3.2 & Domba & Tipe 1 & - \\
\hline IV & Produksi Penggalian & & \\
\hline 1.1 & Pasir & Tipe 1 & Tipe 2 \\
\hline 1.2 & Lainnya & Tipe 2 & - \\
\hline v & Produksi Perikanan & & \\
\hline 5.1 & Kolam & - & - \\
\hline VI & Produksi Industri & & \\
\hline 6.1 & Tahu & Tipe 2 & - \\
\hline 6.2 & Ledre & Tipe 2 & - \\
\hline 6.3 & Tempe & - & - \\
\hline 6.4 & Anyaman Bambu & - & - \\
\hline 6.5 & Anyaman Pandan & - & - \\
\hline 6.6 & Gerabah & - & - \\
\hline 6.7 & Bubut Kayu & - & Tipe 2 \\
\hline 6.8 & Genteng & - & Tipe 2 \\
\hline
\end{tabular}

Berdasarkan tabel di atas, maka
komoditi unggulan masing-masing
kecamatan yang dapat dikembangkan
dengan klasifikasi tipe satu (1) atau
Kecamatan yang memiliki pertumbuhan

cepat di tingkat kecamatan karena komoditi unggulan ini mampu memenuhi kebutuhan daerahnya dan daerah lain adalah: Kecamatan Padangan dengan komoditi unggulan; kacang tanah, tebu, domba, dan galian pasir, dan Kecamatan Kasiman dengan komoditi unggulan ; padi, kacang tanah dan tebu. Sedangkan komoditi unggulan masing-masing kecamatan yang dapat dikembangkan dengan klasifikasi tipe dua (2) atau kecamatan yang mampu memenuhi kebutuhan daerahnya dan daerah lain, tetapi komoditi ini memiliki pertumbuhan yang relatif lambat di tingkat kecamatan adalah: Kecamatan Padangan dengan komoditi unggulan; padi, kedelai, kacang hijau, area tanah kering, tahu, ledre, galian dan Kecamatan Kasiman dengan komoditi unggulan; kacang hijau, kelapa, sapi, galian pasir, bubut kayu dan genteng.

\section{Analisis Hierarki pelayanan Kecamatan berdasarkan Scalogram}

Analisis ini digunakan untuk mengidentifikasi peranan suatu kecamatan berdasarkan pada kemampuan kecamatan tersebut dalam memberikan pelayanan kepada masyarakat dan pelaku ekonomi. Semakin lengkap pelayanan diberikan menunjukkan bahwa kecamatan tersebut mempunyai tingkatan yang semakin tinggi. Kemampuan kecamatan dalam memberikan pelayanan ditunjukkan dengan ketersediaan fasilitas yang dimiliki oleh setiap kecamatan. Semakin bervariasi dan lengkap fasilitas suatu kecamatan menunjukkan bahwa kecamatan tersebut mampu memberikan pelayanan yang lebih lengkap kepada masyarakat dibandingkan dengan kecamatan yang lain. Kondisi inilah yang mengakibatkan suatu kecamatan berperan sebagai suatu pusat pertumbuhan serta menjadi daya tarik bagi kecamatan disekitarnya.

Fasilitas yang akan dianalisis dengan scalogram dalam penelitian ini dikelompokkan menjadi dua kelompok yaitu:

1. Fasilitas yang berkaitan dengan aktivitas ekonomi (perekonomian) 
Suning: Identifikasi Sektor Ekonomi Basis (Unggulan) dan Hierarki Pusat Pelayanan Berdasarkan Tingkat Kemampuan Fasilitas Dalam Rangka Pengembangan Wilayah (Studi Kecamatan Kasiman dan Kecmatan Padangan Kabupaten Bojonegoro.

2. Fasilitas yang berkaitan aktivitas social (pendidikan dan kesehatan)

Menurut Budiharsono (2001), metode ini mempunyai beberapa keunggulan, antara lain:

1. Secara cepat dapat mengorganisasikan data dan mengenal wilayah.

2. Membandingkan pemukimanpemukiman dan wilayah - wilayah berdasarkan Ketersediaan fasilitas pelayanan.

3. Memperlihatkan hierarki pemukiman atau wilayah.

4. Secara potensial dapat digunakan untuk merancang fasilitas baru dan memantaunya.

Tahapan-tahapan yang dilakukan dalam analisis dengan metode skalogram adalah:
1. Kecamatan tersebut disusun urutannya berdasarkan jumlah jenis fasilitas yang dimiliki.

2. Fasilitas-fasilitas disusun urutannya berdasarkan jumlah wilayah yang memiliki jenis fasilitas tersebut.

3. Peringkat jenis fasilitas disusun urutannya berdasarkan jumlah total unit. Kemudian perhitungan metode scalogram dengan melakukan standarisasi dengan nilai minimum dan nilai standar deviasinya. Pengurutan tingkat hierarki adalah berdasarkan pengkumulatifan dari nilai masing-masing fasilitas kecamatan. Urutan teratas merupakan tingkat hierarki terbesar, demikian seterusnya hingga urutan hierarki terkecil.

Hasil perhitungan Scalogram seperti pada tabel 4 dan 5 .

Tabel. 4

Hasil perhitungan fasilitas fisik dengan menggunakan metode skalogram

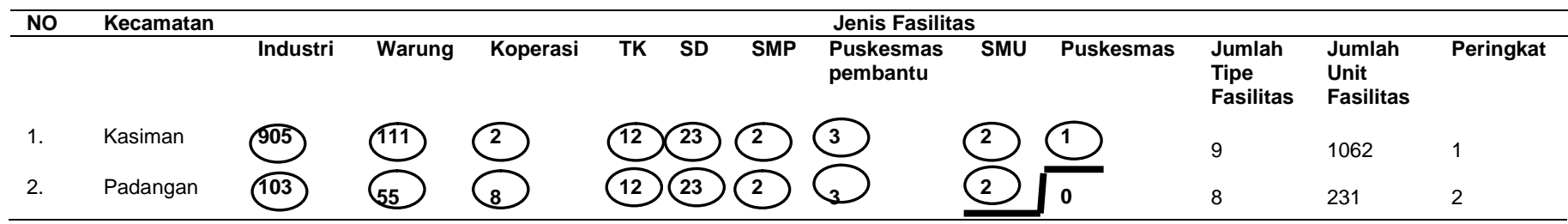

Tabel 5 Hierarki Pelayanan Fasilitas Kecamatan

\begin{tabular}{llc}
\hline NO & Kecamatan & Hierarki \\
\hline 1. & Kasiman & I \\
2. & Padangan & II \\
\hline
\end{tabular}

Sumber: Kecamatan dalam angka Kabupaten Bojonegoro 2004 diolah

Berdasarkan hasil perhitungan analisis scalogram di atas, dapat diketahui bahwa kecamatan yang mempunyai fasilitas terlengkap adalah kecamatan yang memiliki peringkat atau hierarki 1 dari keseluruhan unit fasilitas kecamatan yaitu Kecamatan Kasiman, yang mana kecamatan ini memiliki fasilitas kesehatan dan fasilitas ekonomi terlengkap dibanding dengan kecamatan lain. Kecamatan Padangan memiliki peringkat atau hierarki 2 dari keseluruhan unit fasilitas kecamatan yaitu fasilitas kesehatan dan fasilitas pendidikan paling lengkap dibanding dengan kecamatan lain. Dari uraian analisis scalogram ini dapat disimpulkan bahwa Kecamatan Kasiman merupakan kecamatan yang mampu memberikan pelayanan terbaik kepada masyarakatnya serta mampu menjadi kecamatan pusat pertumbuhan. Dengan demikian kecamatan ini akan menjadi kecamatan utama dan menjadi daya tarik bagi kecamatan sekitarnya atau hiterlandnya. 
Suning: Identifikasi Sektor Ekonomi Basis (Unggulan) dan Hierarki Pusat Pelayanan Berdasarkan Tingkat Kemampuan Fasilitas Dalam Rangka Pengembangan Wilayah (Studi Kecamatan Kasiman dan Kecmatan Padangan Kabupaten Bojonegoro.

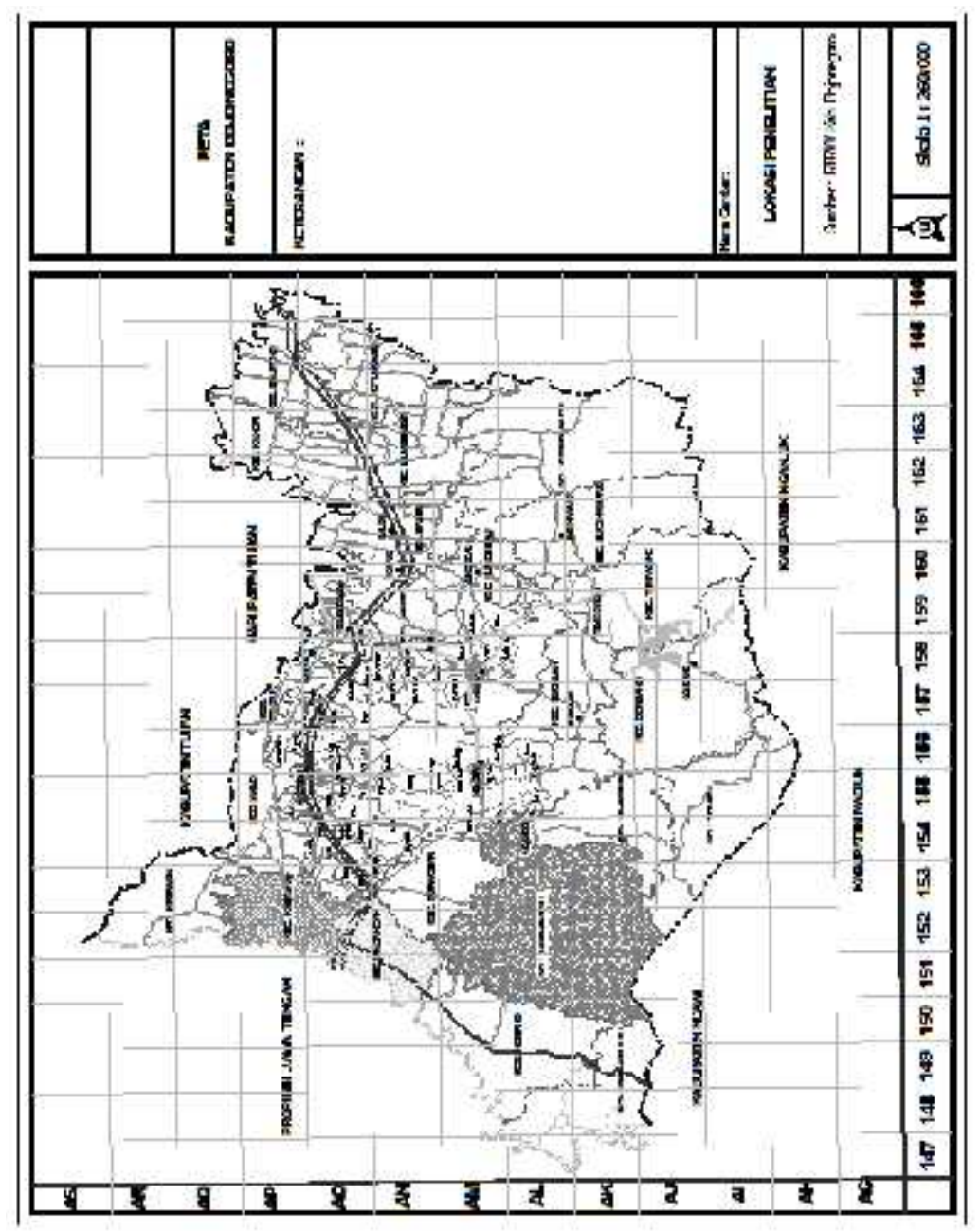

\section{KESIMPULAN Kesimpulan}

Berdasarkan analisa hasil penelitian mengenai Identifikasi Sektor Ekonomi Basis (Unggulan) dan Hierarki Pusat Pelayanan Berdasarkan Tingkat Kemampuan Fasilitas di Kecamatan Kasiman dan Kecamatan Padangan Kabupaten Bojonegoro, maka diperoleh kesimpulan sebagai berikut:

1. Dengan alat analisis perkembangan ekonomi (LQ-SSPS) diperoleh bahwa sumber potensi ekonomi yang dapat dikembangkan di masing-masing kecamatan adalah kecamatan yang memiliki komoditi unggulan dengan klasifikasi tipe 1 atau kecamatan yang memiliki pertumbuhan cepat di tingkat kecamatan karena, memiliki komoditi unggulan yang mampu memenuhi kebutuhan daerahnya dan daerah lain. Dan kecamatan dengan tipe 2 atau kecamatan yang mampu memenuhi kebutuhan daerahnya dan daerah lain, tetapi komoditi ini memiliki pertumbuhan yang relatif lambat di tingkat kecamatan.

2. Dengan analisis fasilitas fisik berdasarkan scalogram diperoleh gambaran bahwa kecamatan yang memiliki fasilitas paling lengkap adalah Kecamatan Kasiman dengan jumlah fasilitas sebanyak 1062 unit dan Kecamatan Padangan sebanyak 231 unit. Dengan demikian Kecamatan Kasiman merupakan kecamatan utama atau Kecamatan dengan kategori orde satu dan Kecamatan Padangan menjadi Kecamatan dengan kategori orde dua yang tentunya akan menjadi daya tarik bagi kecamatan sekitarnya atau hiterlandnya. 


\section{DAFTAR PUSTAKA}

Arsyad, Lincolin. (1999) Pengantar Perencanaan dan Pembangunan Ekonomi Daerah. BPFE, Yogyakarta

Ambert. (1995) dalam Tikno. (2005) Analisis Potensi dan Daya Saing Kecamatan Sebagai Pusat Pertumbuhan Satuan Wilayah Pengembangan (SWP) Kabupaten Malang, Tesis S-2 Program Pascasarjana Unibraw, tidak dipublikasikan

Azis, Iwan J. (1994) Ekonomi Regional dan Beberapa Aplikasi IImu Ekonominya. BPEP- UI. Jakarta

Blakely. Edward. J. (1994) Planning Development Theory and Practice. Second Edition, USA, Sage Publication.

Bappeda Kabupaten Bojonegoro. (2003) Profil Potensi Industri Kecil dan Perdagangan Dalam Rangka Membuka Peluang Investasi Di Kabupaten Bojonegoro.

Bojonegoro Dalam Angka. (2003) Badan Pusat Statistik Kabupaten Bojonegoro.

Bojonegoro Dalam Angka. (2004) Badan Pusat Statistik Kabupaten Bojonegoro

Budiharsono, Sugeng. (2001) Teknik Analisis Pembangunan Wilayah Pesisir dan Lautan. PT. Pradnya Paramita. Jakarta

Fujita Masahisa, Krugman Paul, Venables .J. Anthony. (1999) The Spatial Economy, Cities, Regional, and International Trade. Massachusetts Institute of Technology.

Haerudin, Andi. (2001) Identifikasi Kecamatan Sebagai Pusat Pertumbuhan Wilayah di Kabupaten Soppeng 1994/1995-1999/2000, Tesis S-2 Program Pascasarjana UGM, Tidak dipublikasikan.

Koestoer, H.Raldi. (2001) Dimensi Keruangan Kota Teori \& Kasus. UI-Press.

Kuncoro M. (2001) Analisis Spasial dan Regional (Studi Aglomerasi dan Kluster Industri Indonesia. UPP AMPYKPN, Yogyakarta

L.Saati, Thomas. (1991) Pengambilan Keputusan-Bagi Para Pemimpin. PT. Dharma Aksara Perkasa.

Pemerintah Daerah Jawa Tengah dan Dinas Permukiman \& Tata Ruang. (2004) Lokakarya Penyusunan Rencana Tata Ruang Kawasan Ratubangnegoro. PT. Saranabudi Prakarsaripta

Pemerintah Kabupaten Bojonegoro, Badan Perencanaan Pembangunan Daerah. (2002) RUTRK IKK Purwosari.

Pemerintah Kabupaten Bojonegoro. (2002) RUTRK, RDTRK Kecamatan Padangan

Tarigan, Robinson. (2004) Perencanaan Pembangunan Wilayah. Bumi Aksara.

Tambunan, Tulus. (1996) Tingkat dan Pertumbuhan PDRB serta Kontribusi Sektoral di Kawasan Indonesia Timur: Suatu analisis empiris. Jurnal Ekonomi dan Pembangunan. Vol IV ISSN X.27$\underline{55}$.

Yunus, H. Sabari. (2004) Struktur Tata Ruang Kota. Pustaka Pelajar 